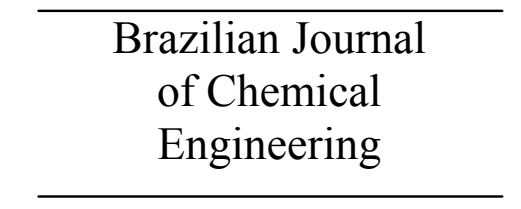

ISSN 0104-6632

Printed in Brazil

www.abeq.org.br/bjche

Vol. 27, No. 01, pp. 89 - 99, January - March, 2010

\title{
OPTIMIZATION OF NAPTHALENE BIODEGRADATION BY A GENETIC ALGORITHM BASED RESPONSE SURFACE METHODOLOGY
}

\author{
M. Zafar*, Shashi Kumar and Surendra Kumar \\ Chemical Engineering Department, Indian Institute of Technology Roorkee, \\ Phone: + (91) 1332-285714, Fax: + (91) 1332-285822, Roorkee-247 667 (UA), India. \\ E-mail: zafar_iet@yahoo.co.in, E-mail:sashifch@iitr.ernet.in, \\ E-mail: skumar@iitr.ernet.in \\ (Submitted: March 3, 2009 ; Revised: October 30, 2009 ; Accepted: November 30, 2009)
}

\begin{abstract}
Naphthalene biodegradation was studied using the bacterial strain Pseudomonas putida S2. Three medium variables out of seven medium components were selected under Plakett-Burman (PB) design as having significant response on naphthalene biodegradation. These variables were citric acid (additional carbon sources), ammonium sulfate and sodium chloride. The levels of these three variables were optimized by the application of genetic algorithm (GA) based response surface methodology (RSM) in terms of maximum biodegradation efficiency. The maximum biodegradation efficiency of $55.51 \%$ was observed at concentrations of $1.0 \mathrm{~g} \mathrm{~L}^{-1}, 1.0 \mathrm{~g} \mathrm{~L}^{-1}$, and $0.7 \mathrm{~g} \mathrm{~L}^{-1}$ for citric acid, ammonium sulfate and sodium chloride, respectively. In addition, the interactive effects of significant medium variables were analyzed using three dimensional surface plots simulated by network output in terms of maximum fitness function.

Keywords: Biodegradation; Naphthalene; Plakett-Burman design; Genetic Algorithm; Response Surface Methodology.
\end{abstract}

\section{INTRODUCTION}

With the awareness of the potential adverse effects of hazardous materials on human health and the environment, remediation and reclamation of land-site contamination is encouraged. Polycyclic aromatic hydrocarbons (PAHs) are one such material and are found in high concentrations on many industrial sites, such as oil and gas combustion for commercial energy generation, sites associated with spills and leaks from storage tanks, and those involving transport, processing, use and disposal of these fuel/oil products (Wilson and Jones, 1993). PAHs are also found in the environment as a result of the incomplete combustion of organic matter, domestic matter (e.g., tobacco smoke, residential wood or coal combustion) and area source matter (e.g., forest fires, and agricultural burning). PAHs are considered as environmental pollutants because they have detrimental effects on the flora and fauna of ecosystem. The uptake and accumulation of these pollutants in food chains lead to serious health problems and genetic defects in humans (Samanta et al., 2002). Due to low solubility in water, most of the PAHs are bound to soil particulates and sediments in aquatic and terrestrial ecosystem and recalcitrant to biodegradation. Naphthalene (two-rings) is one of the members of the PAHs group that has many industrial uses and has been detected in soil, oilcontaminated sediments, and in both industrial and urban wastewater (Nigam et al., 1998). Its concentration varies between $1-4000 \mathrm{mg}$ per kg dry

*To whom correspondence should be addressed 
matter from surface soil to subsoil (Wilson and Jones, 1993). The toxicity and cataractogenic activity of naphthalene has been reported in laboratory animals. It binds covalently to molecules in liver, kidney and lung tissues. It is also an inhibitor of mitochondrial respiration. Acute naphthalene poisoning leads to haemolytic anaemia and nephrotoxicity in human beings (Samanta et al., 2002).

Biological transformation by bacteria and fungi is an important mechanism of PAH removal from terrestrial environments under bioremediation. In the last decade, numerous microbial strains have been identified and characterized which are capable of degrading the PAHs and of forming less toxic products (Boonchen et al., 2000). Some characteristic filamentous fungi have specific bioactivity and growth morphology, and are recognized as better potential degraders of PAHs. Among fungi, the most extensive studies have been carried out on Phanerochaete chrysosporium, Trametes versicolor, Pleurotus ostreatus, Cunninghamella elegans, Penicillium, and $T$. harzianum (Mollea et al., 2005). The known bacterial strains that efficiently degrade PAHs are Pseudomonas putida, $P$. fluorescens, $P$. paucimobilis, $P$. cepacia, Corynebacterium venale, Streptomyces sp., Rhodococcus sp., Mycobacterium sp., Oscillatoria sp., and Alcaligenes sp. (Wilson and Jones, 1993, Boonchen et al., 2000).

Various technologies and procedures of bioremediation are currently being used, and a number of promising approaches have been suggested. Some of these technologies applied for in situ biodegradation, in which subsurface pollution is degraded, are based on stimulation of growth of microorganisms indigenous to the subsurface. The growth and biodegradation efficiency of bacteria need to be optimized for further simulation of in situ conditions. By supplying oxygen (or any other electron acceptor) and nutrients, microorganisms can accelerate the groundwater/subsurface PAHs biodegradation. Addition of a carbon source as a nutrient increases the biomass of soil microorganism, but may inhibit the biodegradation of contaminants with diauxic growth (Lee et al., 2003). So it is important to add the optimal amount of nutrients that can accelerate in situ biodegradation.

The reduction of invested time and cost for development and improvement of in situ bioremediation processes is a fundamental demand. In this specific application, the aim of the optimization is to determine the most suitable bioremediation conditions such as $\mathrm{pH}$, temperature, etc., and added nutrients (medium variables) that maximize the biodegradation efficiency. Some recent innovations are available that incorporate the use of advanced mathematical tools in bioprocess optimization. Concerning the experimental optimization of medium variables, the use of stochastic search procedures based on genetic algorithm (GA) has been applied in an efficacious manner with statistical design of experiments. Statistical methods give better interpretation of optimized response in term of variance, while GA gives better point of prediction. GA is capable of exploring large variable spaces with the additional advantage of an evolutionary adaptation through selection, information exchange (crossing over) and mutation. The strategy "survival of the fittest" is applied according to the optimization objectives. Statistical design of experimentation under response surface methodology (RSM) reduces the cost of experimentation and a collection of statistical and regression techniques provides information about the main and interaction effect among the selected variables (Weuster-Botz, 2000). Presently, GA application to the quadratic model of RSM and hybrid GA-ANN (Artificial Neural Network) are becoming popular for bioprocess parameters optimization. The recent studies include the application of GA for reduction of burr size in drilling process using a RSM based model (Gaitonde et al., 2005), experimental multi-objective medium optimization using GA supported by ANN (Franco Lara et al., 2006), optimization of exo-polysaccharide production by hybrid methodology comprising Plackett-Burman design, ANN and GA (Desai et al., 2006), optimization of $\delta$-endotoxin production by RSM and ANN (Moreira et al., 2007), modeling and optimization of fermentation factor for alkaline protease production using a feed-forward neural network and GA (Rao et al., 2007), optimization of fermentation media using neural network and genetic algorithm (Nagata and Chu, 2003), and optimization of biodegradation of naphthalene by an isolated microorganism by response surface methodology (Martin et al., 2003).

The effect of an additional carbon substrate such as salicylate, catechol, succinate, and glucose on biodegradation of naphthalene has been thoroughly studied in the open literature (Cox et al., 1979; Filonov et al., 2000; Nigam et al., 1998; Lee et al., 2003). Studies on citric acid as the additional carbon source have not been reported yet. Therefore, in the present study, the effect of the additional carbon source citric acid on naphthalene biodegradation is investigated. The other variables whose effects on naphthalene biodegradation are investigated are taken from the Minimal Medium defined by Lee et al. (2003). These variables were $\mathrm{K}_{2} \mathrm{HPO}_{4}, \mathrm{KH}_{2} \mathrm{PO}_{4}$, $\mathrm{NaCl}, \mathrm{MgSO}_{4}, \mathrm{FeSO}_{4} \cdot 7 \mathrm{H}_{2} \mathrm{O}$ and $\left(\mathrm{NH}_{4}\right)_{2} \mathrm{SO}_{4}$. The 
objective of the present work is to model and optimize the degradation of naphthalene (a PAH model compound) by Pseudomonas putida strain S2 in an agitated biphasic culture system. The significant components of defined Minimal Medium (Lee et al., 2003) with citric acid (additional carbon source) were screened under Plakett-Burman (PB) design. The levels of screened significant variables were further optimized by the application of GA to a RSM based quadratic model. Interaction effects of significant medium variables are also investigated in the present work. Mathematical modeling is integrated with statistical experimentation techniques for better interpretation of results and experimental errors. Elucidation of the optimal naphthalene biodegradation conditions provides the information for further scaling of in situ biodegradation processes.

\section{MATERIALS AND METHODS}

\section{Microbial Strain and Culture Conditions}

Pseudomonas putida strain S2 was isolated from petroleum-contaminated soil (near storage tank) by deep inoculation methods with naphthalene as a sole source of carbon. The successive screened precultures were grown on nutrient agar (naphthalene supplemented) at $28^{\circ} \mathrm{C}$ and stored at $4^{\circ} \mathrm{C}$. Naphthalene adapted precultures was also grown well on minimal medium of Pseudomonas which contained, per litre, $3.0 \mathrm{~g} \mathrm{~K}_{2} \mathrm{HPO}_{4}, 1.5 \mathrm{~g} \mathrm{KH}_{2} \mathrm{KO}_{4}, 0.01 \mathrm{~g} \mathrm{NaCl}, 0.1 \mathrm{~g}$ $\mathrm{MgSO}_{4}, 0.001 \mathrm{~g} \mathrm{FeSO}_{4} .7 \mathrm{H}_{2} \mathrm{O}$ and $1.0 \mathrm{~g}$ of $\left(\mathrm{NH}_{4}\right)_{2} \mathrm{SO}_{4}$. The $\mathrm{pH}$ was adjusted at 7.0 (Lee et al., 2003). All the chemicals used for the culture media were of analytical grade and obtained from Hi Media Laboratories Pvt. Ltd, Mumbai, India, and S.D. Fine Chemical Ltd, Mumbai, India.

\section{Analytical Procedures}

The utilization of naphthalene by bacterial cells was monitored from residual naphthalene samples, which was taken periodically from the organic phase of the biphasic system under sterile conditions. The samples were centrifuged at $10,000 \mathrm{rpm}$ for 5 minutes to separate the emulsified liquid phases. The amount of naphthalene in n-paraffin (organic phase) was quantified by measuring the absorbance at 275 $\mathrm{nm}$ in a UV-VIS Spectrophotometer (Lambada35, Perkin Elmer, MA 02451). A standard calibration curve was prepared by plotting a given range of substrate (naphthalene) concentration against its measured absorbance. The curve was linear with correlation coefficient $\mathrm{R}^{2}=0.99$. The suitable dilution was made by following the Beer-Lambert Law. The absorbance of residual naphthalene was measured and percentage degradation efficiency was calculated from the slope of the standard calibration curve.

\section{Experimental System and Conditions}

A non-aqueous-phase liquid (NAPL) system was considered promising because it overcomes the low solubility of PAHs and enhances their bioavailability (Ascon-Cabrera and Lebeault, 1993). In the present optimization study of naphthalene degradation, experiments were conducted in a biphasic cultivation system at the shake flask level. The biphasic cultivation system NAPL consisted of naphthalene in n-paraffin (organic phase) with aqueous phase (for bacterial cell growth) in the ratio of 2:3. The seed culture of $P$. putida S2 was prepared in defined minimal medium (Lee et al., 2003) and used as the source of inoculum to inoculate the $250 \mathrm{ml}$ capacity Erlenmayer flasks containing $50 \mathrm{~mL}$ liquid volume of organic to aqueous phase in the above mentioned ratio. The bacterial cells were counted by the drop plate technique and a concentration of approximately $3 \times 10^{5}$ cells per $\mathrm{mL}$ of culture broth was kept as initial inoculum size of liquid volume. The initial concentration of naphthalene was kept at $100 \mathrm{ppm}$ in NAPL (n-paraffin). The inoculated flasks were kept for 72 hours in an orbital shaking incubator (Metrex Scientific Instruments (P) Ltd., New Delhi, India) with shaking speed $165 \mathrm{rpm}$ and temperature $28^{\circ} \mathrm{C}$. Experiments were conducted in specific design fashions (PB design and central composite design) and medium components were kept within the selected range (given in Table 1).

\section{Table 1: Medium variables and their concentration levels for the RSM Model}

\begin{tabular}{|c|c|c|c|c|c|c|}
\hline \multirow{2}{*}{ Medium Variables } & \multirow{2}{*}{ Unit } & \multicolumn{5}{|c|}{ Levels } \\
\hline & & $-\alpha(-1.682)$ & -1 & $\mathbf{0}$ & +1 & $+\alpha(+1.682)$ \\
\hline $\begin{array}{l}\text { Citric acid } \\
\left(\mathrm{NH}_{4}\right)_{2} \mathrm{SO}_{4} \\
\mathrm{NaCl}\end{array}$ & $\begin{array}{l}\mathrm{gL}^{-1} \\
\mathrm{gL}^{-1} \\
\mathrm{gL}^{-1}\end{array}$ & $\begin{array}{r}0.6580 \\
0.1580 \\
0.000\end{array}$ & $\begin{array}{r}1 \\
0.5 \\
0.03\end{array}$ & $\begin{array}{r}1.5 \\
1.0 \\
0.05\end{array}$ & $\begin{array}{r}2 \\
1.5 \\
0.1\end{array}$ & $\begin{array}{l}2.3410 \\
1.8410 \\
0.1341\end{array}$ \\
\hline
\end{tabular}


Plackett-Burman (PB) Statistical Technique for Screening Media Components

Modeling of a process is required to reduce the multiple input variables of a process into a desired smaller number that have a significant influence on the output response. PB design statistically evaluates and reduces a set of variables into significant ones. This method allows the evaluation of $(\mathrm{N}-1)$ variables under $\mathrm{N}$ number of experiments $(\mathrm{N}$ must be a multiple of four). Each variable is represented at two levels as 'high' and 'low' to cover the defined upper and lower limits of the variable range. In the PB design, experiments were performed at various combinations of high and low values of the process variables and their effect was analyzed by statistical means. Dummy variables were introduced into experimentation to estimate the experimental error of an effect. The variables, whose effects were negligible under high and low concentrations, were considered as dummy variables.

In the present study, the components of minimal medium (Lee at al., 2003) with added citric acid (seven variables) were screened in eight experiments (Table 2) of combinations of low (L) and high (H) variable concentrations with two replications. The low and high concentrations of variables (in $\mathrm{g} \mathrm{L}^{-1}$ ) were, citric acid $\left(\mathrm{X}_{1}\right), \mathrm{L} 1.0, \mathrm{H}$ 2.0., $\left(\mathrm{NH}_{4}\right)_{2} \mathrm{SO}_{4}\left(\mathrm{X}_{2}\right)$, $\mathrm{L}$ 0.5, H 1.5., $\mathrm{K}_{2} \mathrm{HPO}_{4}\left(\mathrm{X}_{3}\right), \mathrm{L}$ 2.0, H 3.0., $\mathrm{KH}_{2} \mathrm{PO}_{4}$ $\left(\mathrm{X}_{4}\right), \mathrm{L}$ 0.75, $\mathrm{H}$ 1.5., $\mathrm{MgSO}_{4}\left(\mathrm{X}_{5}\right), \mathrm{L} 0.05, \mathrm{H} 0.10$., $\mathrm{NaCl}\left(\mathrm{X}_{6}\right), \mathrm{L} 0.05, \mathrm{H} 0.10$., and $\mathrm{FeSO}_{4} .7 \mathrm{H}_{2} \mathrm{O}\left(\mathrm{X}_{7}\right) \mathrm{L}$ $0.001 \mathrm{H} 0.002$. The average response of variables was subjected to statistical analysis to screen the significant variables.

\section{Central Composite Design of Experimentation}

The optimization of naphthalene biodegradation efficiency (\%) was performed at the shake flask level by utilizing the response surface methodology based on the central composite design (CCD) of experimentations. In the investigation, the medium variables were selected for level optimization based on prior screening under $\mathrm{PB}$ screening design. A three-level half-replicated second-order CCD was used to study linear, quadratic, and two factor interaction effects between these three variables and response. The upper limit of a factor was coded as $+1.682(+\alpha$ level $)$ and the lower limit as $-1.682(-\alpha$ level).

Central composite rotatable design comprises $2^{\mathrm{n}}$ factorial point experiments along with star points and center point experiments. All factors at the intermediate (0) level constitute the center points and the combinations of each of the biodegradation variables at either its lowest (-1.682) or highest $(+1.682)$ level with the other variables of the intermediate levels constitute the star points. The above model has been reduced to three variables, citric acid, $\left(\mathrm{NH}_{4}\right)_{2} \mathrm{SO}_{4}$ and $\mathrm{NaCl}$ which have been screened under $\mathrm{PB}$ design of experimentation as having significant response. The experiments were conducted in specific design fashion (CCD) with two replications (Table 4) at the shake flask level as described in the section experimental system and condition. The observed responses (ND \%) were subjected to Design Expert (V 6.0.10, Stat-Ease Inc., Minneapolis, 2004) for the analysis of variance (ANOVA) and regression.

\section{Postulation of Mathematical Model: Quadratic Model}

A second order quadratic mathematical model was developed to predict the influence of various medium variables on the naphthalene degradation (\%) and reduced to three variables for GA based optimization. The response surface equation for three variables adopted in the present case is of the following form:

$$
\begin{aligned}
\mathrm{Y}_{\mathrm{ND}}= & \mathrm{b}_{0}+\mathrm{b}_{1} \mathrm{X}_{1}+\mathrm{b}_{2} \mathrm{X}_{2}+\mathrm{b}_{3} \mathrm{X}_{3}+ \\
& \mathrm{b}_{11} \mathrm{X}_{1}{ }^{2}+\mathrm{b}_{22} \mathrm{X}_{2}{ }^{2}+\mathrm{b}_{33} \mathrm{X}_{3}{ }^{2}+ \\
& \mathrm{b}_{12} \mathrm{X}_{1} \mathrm{X}_{2}+\mathrm{b}_{23} \mathrm{X}_{2} \mathrm{X}_{3}+\mathrm{b}_{13} \mathrm{X}_{1} \mathrm{X}_{3}
\end{aligned}
$$

where $Y_{N D}$ is the desired response, $b_{0}, b_{1}, b_{2}, b_{3}, b_{11}$, $b_{22}, b_{33}$ and $b_{12}, b_{13}, b_{23}$ are the regression coefficients to be determined. $\mathrm{X}_{1}, \mathrm{X}_{2}$, and $\mathrm{X}_{3}$ are the coded values of the significant variables citric acid, $\left(\mathrm{NH}_{4}\right)_{2} \mathrm{SO}_{4}$ and $\mathrm{NaCl}$, respectively.

The values of the regression coefficient of the linear, quadratic and interaction terms of the models were determined using the software Design-Expert. The adequacy of the models was checked by F-test at $95 \%$ confident levels and only the significant variable terms were included in the model in order to predict the response as a function of the significant variables.

\section{Development of GA for Optimization of Input Parameters Under the Quadratic Model}

The developed quadratic model for naphthalene biodegradation is used to optimize the process variables by application of GA, with a view of maximizing the process performance. The optimization objective is defined such as to find the 
three-dimensional optimal decision variable vector, $\mathrm{x}^{*}=\left[\mathrm{x}_{1}{ }^{*}, \mathrm{x}_{2}{ }^{*}, \mathrm{x}_{3}{ }^{*}\right]$, such that it maximizes the objective function $\mathrm{f}\left(\mathrm{x}^{*}, \mathrm{w}\right)$.

Under GA-based search, genes are the searching parameters represented in the form of binary ( 0 and 1$)$ or real valued strings (chromosomes). The chromosomes for the optimization consist of three genes corresponding to three searching parameters (citric acid, $\left(\mathrm{NH}_{4}\right)_{2} \mathrm{SO}_{4}$, and $\mathrm{NaCl}$ ). Each gene is represented by 20 bits of binary codes and hence each chromosome is represented by 60 bits.

$$
\text { Chromosome }=[\mathrm{A}, \mathrm{B}, \mathrm{C}]
$$

where $\mathrm{A}$ is concentration of citric acid, $\mathrm{B}$ is concentration of $\left(\mathrm{NH}_{4}\right)_{2} \mathrm{SO}_{4}$, and $\mathrm{C}$ is concentration of $\mathrm{NaCl}$.

The optimization process is initialized with 50 randomly selected chromosomes generated as the initial generation. The genes of each chromosome are decoded as:

$$
\begin{aligned}
& \mathrm{X}=\mathrm{D} \frac{\left(\mathrm{X}_{\max }-\mathrm{X}_{\min }\right)}{\mathrm{D}_{\mathrm{c}}}+\mathrm{X}_{\min } ; \mathrm{X}=\mathrm{A}, \mathrm{B}, \mathrm{C} \\
& \mathrm{D}_{\mathrm{c}}=\sum_{\mathrm{i}=1}^{\mathrm{bt}} 2^{\mathrm{bt}}=\text { Sum of all binary weights of each bit }
\end{aligned}
$$

bt is the bit length and $\mathrm{D}$ is decimal equivalence of binary digit.

Fitness function is the performance index of a GA to resolve the validity of each chromosome and chromosomes are evaluated to measure its fitness to fulfill the optimization objective (maximum naphthalene biodegradation). In the case of experimental design with GA, it is necessary to work with minimum population size. Selection is the operator which carries old chromosomes into new populations and is proportional to the fitness. Crossover is a recombination operator where genes information is exchanged at random locations between two parent chromosomes, which are randomly selected highly fit chromosomes from the population. The crossover locations are randomly selected and 'single point' crossover takes place with the highest possible probability (90-100 \%) (Weuster-Botz, 2000). The crossover formed between selected chromosome pairs (Nc) can be represented as,

$$
\mathrm{N}_{\mathrm{C}}=\frac{\mathrm{N} \cdot \mathrm{pc}}{2}
$$

where $\mathrm{N}=$ No. of chromosomes in the 50 populations.

The numbers of crossovers are approximately 23, with the crossover probability (pc) as 0.90 (assumption), performed between randomly selected pairs among 45 highly fit chromosomes. The probability of the success of a point mutation depends on the mutation rate and the current fitness of a binary character string. A mutation rate $\left(\mathrm{P}_{\mathrm{m}}\right)$ is inversely proportional to the binary character string length $\left(\mathrm{P}_{\mathrm{m}}>1 / \mathrm{L}\right)$ and mutation operation consists of complementing the bits (replacing 0 by 1 and vice versa) at random locations. Assuming the mutation probability $\left(\mathrm{P}_{\mathrm{m}}\right)$ as 0.01 , the number of mutations is,

$\mathrm{N}_{\mathrm{m}}=\mathrm{P}_{\mathrm{m}} \mathrm{nN}$

where $\mathrm{n}$ is the length of chromosome, which is $=60$.

This gives $\mathrm{N}_{\mathrm{m}}=30$. Thus, 5-bit mutations were performed at random locations on 30 least-fit chromosomes in the population.

The principal steps in the GA optimization are:

i) Generate randomly an initial chromosome population.

ii) Decode the genes Citric acid, $\left(\mathrm{NH}_{4}\right)_{2} \mathrm{SO}_{4}$ and $\mathrm{NaCl}$ of all chromosomes.

iii) With selected variables, evaluate the predicted values of naphthalene degradation using RSM models (Eqn. 1).

iv) Determine the fitness of all chromosomes and obtain the maximum fitness fit ${ }_{\text {max }}$

v) If fit $_{\max } \leq$ fit $_{\text {req }}$, then carry out the next genetic operation to generate a new chromosome population and go to step (ii).

For each generation, selection, recombination and mutation operators are performed to give the optimized solution.

\section{RESULTS AND DISCUSSION}

\section{Selection of Significant Media Components for Naphthalene Biodegradation}

The naphthalene biodegradation medium consists of seven components: $\mathrm{KH}_{2} \mathrm{PO}_{4}, \mathrm{~K}_{2} \mathrm{HPO}_{4}, \mathrm{MgSO}_{4}, \mathrm{NaCl}$, $\mathrm{FeSO}_{4} \cdot 7 \mathrm{H}_{2} \mathrm{O},\left(\mathrm{NH}_{4}\right)_{2} \mathrm{SO}_{4}$, and carbon and energy source citric acid. The significant medium variables are selected which have significant response on biodegradation efficiency. The experiments are performed as the combination of low and high 
concentrations of variables under PB design (Table 2). The results of design experiments analyzed by calculating t-values are given in Table 3. The variables $\left(\mathrm{KH}_{2} \mathrm{PO}_{4}, \mathrm{~K}_{2} \mathrm{HPO}_{4}\right.$, and $\left.\mathrm{FeSO}_{4} .7 \mathrm{H}_{2} \mathrm{O}\right)$ are considered as dummy variables which have little influence on response upon fluctuation. The dummy variables are used as the measure of variability and they give a direct estimate of the standard error of a factor effect.

Table 3 shows that citric acid, $\left(\mathrm{NH}_{4}\right)_{2} \mathrm{SO}_{4}, \mathrm{NaCl}$, and $\mathrm{MgSO}_{4}$ have significant effects on naphthalene biodegradation. The variable citric acid has high response $\left(\sum \mathrm{L}=227.29\right)$ at its low concentration of 1.0 $\mathrm{gL}^{-1}$ and low response $\left(\sum \mathrm{H}=169.5\right)$ at its high concentration of $2.0 \mathrm{gL}^{-1}$. This indicates that biodegradation efficiency decreases with increase in concentration. The possible explanation is that, at high concentration, citric acid may act as diauxic growth promoter and inhibits the biodegradation of naphthalene until it depletes with microbial growth. Here citric acid shows significant fluctuation in response and, therefore, it is selected as a variable to be optimized. Ammonium sulfate, used as a nitrogen source, also shows high significant response on biodegradation. $\mathrm{NaCl}$ and $\mathrm{MgSO}_{4}$ are other variables which show significant response on naphthalene degradation. Further, three variables citric acid, $\left(\mathrm{NH}_{4}\right)_{2} \mathrm{SO}_{4}$, and $\mathrm{NaCl}$ are selected for their level optimization by a set of $20 \mathrm{CCD}$ experimental runs.
$\mathrm{MgSO}_{4}$ will be studied later with other process variables.

\section{GA-Based Optimization of the Quadratic Model for Naphthalene Biodegradation}

Experiments are conducted in CCD fashion to model and optimize naphthalene biodegradation. Tables 1 and 4 shows the medium variables screened with their concentration level to be studied under optimization and the design matrix of CCD experimentation with observed response of naphthalene biodegradation, respectively. The second-order quadratic polynomial equation is fitted by Design-Expert software and is represented for Analysis of Variance (ANOVA) of model terms in Table 5. The model F-value of 5.54 implies that the model is significant enough for regression analysis between response and variable effects. The goodness of fit of the model is checked in terms of the determination of regression coefficient $\left(\mathrm{R}^{2}\right)$. The value 0.8471 of $R^{2}$ indicates that only $15.29 \%$ of the variation around the mean cannot be explained by the model. The value of the adjusted $\mathrm{R}^{2}(0.6941)$, a measure of the amount of variation around the mean explained by the model adjusted for the model terms, also advocates for a high significance of the model (Montgomery, 2001).

Table 2: Plakett-Burman design for screening seven variables

\begin{tabular}{|c|c|c|c|c|c|c|c|c|}
\hline Trial & $\begin{array}{c}\mathbf{X}_{\mathbf{1}} \\
\text { Citric acid }\end{array}$ & $\begin{array}{c}\mathbf{X}_{\mathbf{2}} \\
\left(\mathbf{N H}_{4} \mathbf{S O}_{2} \mathbf{S O}_{\mathbf{4}}\right.\end{array}$ & $\begin{array}{c}\mathbf{X}_{\mathbf{3}} \\
\mathbf{K}_{\mathbf{2}} \mathbf{H P O}_{\mathbf{4}}\end{array}$ & $\begin{array}{c}\mathbf{X}_{\mathbf{4}} \\
\mathbf{K H}_{\mathbf{2}} \mathbf{P O}_{\mathbf{4}}\end{array}$ & $\begin{array}{c}\mathbf{X}_{\mathbf{5}} \\
\mathbf{M g S O}_{\mathbf{4}}\end{array}$ & $\begin{array}{c}\mathbf{X}_{\mathbf{6}} \\
\mathbf{N a C l}\end{array}$ & $\begin{array}{c}\mathbf{X}_{7} \\
\mathbf{F e S O}_{\mathbf{4}} \cdot \mathbf{7} \mathbf{H}_{\mathbf{2}} \mathbf{O}\end{array}$ & $\begin{array}{c}\text { Biodegradation } \\
\text { efficiency (\%) }\end{array}$ \\
\hline 1 & $\mathrm{H}$ & $\mathrm{H}$ & $\mathrm{H}$ & $\mathrm{L}$ & $\mathrm{H}$ & $\mathrm{L}$ & $\mathrm{L}$ & 45.23 \\
2 & $\mathrm{~L}$ & $\mathrm{H}$ & $\mathrm{H}$ & $\mathrm{H}$ & $\mathrm{L}$ & $\mathrm{H}$ & $\mathrm{L}$ & 65.35 \\
3 & $\mathrm{~L}$ & $\mathrm{~L}$ & $\mathrm{H}$ & $\mathrm{H}$ & $\mathrm{H}$ & $\mathrm{L}$ & $\mathrm{H}$ & 48.23 \\
4 & $\mathrm{H}$ & $\mathrm{L}$ & $\mathrm{L}$ & $\mathrm{H}$ & $\mathrm{H}$ & $\mathrm{H}$ & $\mathrm{L}$ & 36.42 \\
5 & $\mathrm{~L}$ & $\mathrm{H}$ & $\mathrm{L}$ & $\mathrm{L}$ & $\mathrm{H}$ & $\mathrm{H}$ & $\mathrm{H}$ & 62.74 \\
6 & $\mathrm{H}$ & $\mathrm{L}$ & $\mathrm{H}$ & $\mathrm{L}$ & $\mathrm{L}$ & $\mathrm{H}$ & $\mathrm{H}$ & 40.62 \\
7 & $\mathrm{H}$ & $\mathrm{H}$ & $\mathrm{L}$ & $\mathrm{H}$ & $\mathrm{L}$ & $\mathrm{L}$ & $\mathrm{H}$ & 47.23 \\
8 & $\mathrm{~L}$ & $\mathrm{~L}$ & $\mathrm{~L}$ & $\mathrm{~L}$ & $\mathrm{~L}$ & $\mathrm{~L}$ & $\mathrm{~L}$ & 50.97 \\
\hline
\end{tabular}

Table 3: Statistical calculations for Plakett-Burman design

\begin{tabular}{|c|c|c|c|c|c|c|c|}
\hline Quantity & Citric acid & $\left(\mathrm{NH}_{4}\right)_{2} \mathrm{SO}_{4}$ & $\begin{array}{c}\mathrm{K}_{2} \mathrm{HPO}_{4} \\
\left(\mathrm{D}_{1}\right)\end{array}$ & $\begin{array}{c}\mathrm{KH}_{2} \mathbf{P O}_{4} \\
\left(\mathrm{D}_{2}\right)\end{array}$ & $\mathrm{MgSO}_{4}$ & $\mathrm{NaCl}$ & $\begin{array}{c}\mathrm{FeSO}_{4} \cdot 7 \mathrm{H}_{2} \mathrm{O} \\
\left(\mathrm{D}_{3}\right)\end{array}$ \\
\hline$\Sigma(\mathrm{H})$ & 169.50 & 220.55 & 199.43 & 197.23 & 192.62 & 205.13 & 198.82 \\
\hline$\Sigma(\mathrm{L})$ & 227.29 & 176.24 & 197.23 & 199.56 & 204.17 & 191.66 & 197.97 \\
\hline$\Sigma(\mathrm{H})-\Sigma(\mathrm{L})$ & -57.79 & 44.31 & 2.20 & -2.33 & -11.55 & 13.47 & 0.85 \\
\hline Effect & 14.45 & 11.08 & 0.55 & 0.58 & 2.88 & 3.37 & 0.21 \\
\hline 't'-value & $30.268^{* * *}$ & 23.209 ** & 1.152 & 1.214 & 6.032 & $7.059 *$ & 0.439 \\
\hline
\end{tabular}


Table 4: Design Matrix (CCD) and observed values of response

\begin{tabular}{|c|c|c|c|c|c|}
\hline Run & Type & Citric acid & $\left(\mathrm{NH}_{4}\right)_{2} \mathrm{SO}_{4}$ & $\mathrm{NaCl}$ & Observed ND \% \\
\hline 1 & Center & 0 & 0 & 0 & 60.84 \\
\hline 2 & Center & 0 & 0 & 0 & 60.68 \\
\hline 3 & Center & 0 & 0 & 0 & 60.80 \\
\hline 4 & Center & 0 & 0 & 0 & 59.64 \\
\hline 5 & Center & 0 & 0 & 0 & 61.20 \\
\hline 6 & Center & 0 & 0 & 0 & 61.12 \\
\hline 7 & Axial & 0 & -1.682 & 0 & 60.24 \\
\hline 8 & Axial & 1.682 & 0 & 0 & 59.84 \\
\hline 9 & Axial & 0 & 0 & -1.682 & 60.64 \\
\hline 10 & Axial & 0 & 1.682 & 0 & 57.60 \\
\hline 11 & Axial & -1.682 & 0 & 0 & 60.28 \\
\hline 12 & Axial & 0 & 0 & 1.682 & 61.64 \\
\hline 13 & Factorial & +1 & -1 & -1 & 57.56 \\
\hline 14 & Factorial & -1 & +1 & -1 & 58.04 \\
\hline 15 & Factorial & +1 & +1 & -1 & 57.12 \\
\hline 16 & Factorial & +1 & +1 & +1 & 59.08 \\
\hline 17 & Factorial & +1 & -1 & +1 & 60.12 \\
\hline 18 & Factorial & -1 & -1 & +1 & 59.64 \\
\hline 19 & Factorial & -1 & -1 & -1 & 56.60 \\
\hline 20 & Factorial & -1 & +1 & +1 & 57.40 \\
\hline
\end{tabular}

Table 5: ANOVA for Response Surface Quadratic Model

\begin{tabular}{|c|c|c|c|c|c|}
\hline Source & Sum of Square & DF & Mean Square & F-Value & Prob $>F$ \\
\hline Block & 8.88 & 1 & 8.88 & & \\
\hline Model (Quadratic) & 31.56 & 9 & 3.51 & 5.54 & 0.0089 (Significant) \\
\hline A & 0.16 & 1 & 0.16 & 0.25 & 0.6314 \\
\hline $\mathrm{B}$ & 3.31 & 1 & 3.31 & 5.22 & 0.0481 \\
\hline $\mathrm{C}$ & 5.42 & 1 & 5.42 & 8.56 & 0.0169 \\
\hline $\mathrm{A}^{2}$ & 5.81 & 1 & 5.81 & 9.17 & 0.0143 \\
\hline $\mathrm{B}^{2}$ & 15.51 & 1 & 15.51 & 24.51 & 0.0008 \\
\hline $\mathrm{C}^{2}$ & 0.92 & 1 & 0.92 & 1.46 & 0.2582 \\
\hline $\mathrm{AB}$ & 0.058 & 1 & 0.058 & 0.091 & 0.7694 \\
\hline $\mathrm{AC}$ & 0.56 & 1 & 0.56 & 0.89 & 0.3708 \\
\hline $\mathrm{BC}$ & 2.29 & 1 & 2.29 & 3.62 & 0.0896 \\
\hline Residual & 5.70 & 9 & 0.63 & & \\
\hline Lack of Fit & 4.72 & 5 & 0.94 & 3.85 & 0.1080 (Non-Significant) \\
\hline Pure Error & 0.98 & 4 & 0.25 & & \\
\hline Cor. Total & 46.13 & 19 & & & \\
\hline
\end{tabular}

At the same time, the relatively low value of the coefficient of variance (CV) $(1.34 \%)$ and high adequate precision (7.69\%) (a measure of signal to noise ratio) indicate a better precision and reliability of the experiments carried out (Montgomery, 2001). The "Lack of Fit" value of 3.85 is non-significant in relation to the pure error, indicating that the $10.80 \%$ chance of this could be due largely to noise (Table 5). A negative "Pred-R Squared" (-0.2162) implies that the overall mean is a better predictor of response.

The value of model coefficient terms whose values of "Prob $>F$ " are less than 0.050 are considered as significant. In this case, model terms
$\mathrm{X}_{2}$ (Ammonium sulfate), $\mathrm{X}_{3}(\mathrm{NaCl}), \mathrm{X}_{1}^{2}\left(\right.$ citric $\left.\mathrm{acid}^{2}\right)$, and $\mathrm{X}_{2}{ }^{2}$ (Ammonium sulfate $\left.{ }^{2}\right)$ are considered as significant ones. In order to improve the model prediction, only significant terms are included in the model. The reduced model which describes the response as a function of significant variables is given below:

$$
\begin{aligned}
& \mathrm{ND}(\%)=48.69681+9.81682\left[\left(\mathrm{NH}_{4}\right)_{2} \mathrm{SO}_{4}\right]+ \\
& 2.71086[\mathrm{NaCl}]-2.53969[\text { Citric acid }]^{2}- \\
& 4.15189\left[\left(\mathrm{NH}_{4}\right)_{2} \mathrm{SO}_{4}\right]^{2}
\end{aligned}
$$


In equation (7), [Citric acid], [( $\left.\left(\mathrm{NH}_{4}\right)_{2} \mathrm{SO}_{4}\right]$, and $[\mathrm{NaCl}]$ represent the actual values of concentration of citric acid, ammonium sulfate and sodium chloride, respectively, used in experiments.

The selected significant RSM model is used to simulate GA based optimization in the GA based optimization toolbox of MATLAB 7.0 (The Mathworks Inc, MA, USA). The simulation of genetic optimization is performed with maximum 300 generations of GA runs and is represented in Figure 1. GA performs the global optimum search as compared to other algorithms, which gives a local optimum solution for the non-linear problems (Weuster-Botz, 2002; Rao et al., 2007).

Table 6 depicts the possible optimal conditions obtained after performing GA runs and the five best conditions among them are selected for further verification. The validity of the model used and GA optimization are tested by conducting experiments on the best predicted conditions. A significant increase in biodegradation efficiency is observed with the optimized variable levels. Maximum biodegradation efficiency of $55.51 \%$ is observed at concentrations of $1.0 \mathrm{~g} \mathrm{~L}^{-1}, 1.0 \mathrm{~g} \mathrm{~L}^{-1}$, and $0.7 \mathrm{~g} \mathrm{~L}^{-1}$ for citric acid, ammonium sulfate and sodium chloride, respectively. Close prediction of biodegradation efficiency $(52.12 \%$ with $52.56 \%$ of experimental) is observed at concentrations of $1.5 \mathrm{~g} \mathrm{~L}^{-1}, 0.5 \mathrm{~g} \mathrm{~L}^{-1}$, and $0.1 \mathrm{~g} \mathrm{~L}^{-1}$ for citric acid, ammonium sulfate and sodium chloride, respectively.

In the present study, the concentration of additional citric acid needed is to be optimized and verified under possible optimized conditions. The verification of optimized conditions showed that the moderate value of citric acid did not lead the diauxic growth and no lag was observed, whereas a high concentration might inhibit the biodegradation of naphthalene by diauxic growth (as shown in PB design). Thus, its required concentration is to be optimized. In the optimized medium, which contains both citric acid and naphthalene, citric acid consumption started at the beginning with constitutive synthesis of enzymes involved in its metabolism. The same result was observed by Lee et al. (2003) with pyruvate as additional carbon source. Citric acid and pyruvate follow the same metabolic pathway for the generation of reducing power (NADPH/NADH) for cell growth and metabolism. The optimized results also imply that $P$. putida $\mathrm{S} 2$ utilizes citric acid without preference over naphthalene. Thus, citric acid can be supplied as additional carbon source to stimulate the degradation of naphthalene in situ.

Ammonium sulfate was another medium variable that showed significant response under PB design. Therefore, it is considered for level optimization under CCD experimentations. Low concentration of ammonium sulfate leads to the maximum biodegradation of naphthalene in validated experiments. The kinetics of ammonium uptake are first order and its specific uptake rate and microbial growth increase as the ammonium ion concentration increases. However, growth and ammonium uptake rate reach a maximum and then decrease with the increase in aqueous ammonium ion concentration due to some possible inhibition mechanism (Annuar et al., 2006). In the optimized medium, moderate concentration favors maximum biodegradation of naphthalene and shows the possible agreement with the findings of Annuar et al. (2006).

Sodium chloride was also screened under PB design and was subjected to its level optimization by GA based on the RSM model. Sodium chloride has a significant effect on naphthalene utilization, biomass growth, and cell surface hydrophobicity (bacterial biofilm formation). The optimized conditions indicate that its slightly higher concentration favors the growth and utilization of naphthalene by the microbial strain. The results are in good agreement with the findings of Kuntiya et al. (2005), where the phenol degradation and cell growth were found to be faster in the presence of sodium chloride with decreased cell surface hydrophobicity.

Table 6: Validation of RSM model developed

\begin{tabular}{|c|c|c|c|c|c|c|}
\hline \multirow{2}{*}{ Run } & \multicolumn{3}{|c|}{ Variable Concentration $\left(\mathrm{gL}^{-1}\right)$} & \multirow{2}{*}{$\begin{array}{l}\text { Predicted Yield } \\
\text { (ND \%) }\end{array}$} & \multirow{2}{*}{$\begin{array}{c}\text { Experimental Yield } \\
\text { (ND \%) }\end{array}$} & \multirow{2}{*}{$\begin{array}{c}\text { Error } \\
(\%)\end{array}$} \\
\hline & Citric acid & $\left(\mathrm{NH}_{4}\right)_{2} \mathrm{SO}_{4}$ & $\mathrm{NaCl}$ & & & \\
\hline 1 & 1.0 & 1.0 & 0.7 & 55.51 & 54.94 & 1.03 \\
\hline 2 & 1.5 & 0.5 & 0.1 & 52.12 & 52.56 & 0.83 \\
\hline 3 & 2.0 & 1.5 & 0.03 & 45.50 & 44.98 & 1.15 \\
\hline 4 & 1.0 & 0.5 & 0.03 & 51.61 & 51.05 & 1.09 \\
\hline 5 & 1.5 & 1.0 & 0.07 & 52.34 & 51.68 & 1.27 \\
\hline
\end{tabular}


Based on experimental results, surface contours are generated to understand the impact of one variable on the other using fitness functions with the help of MATLAB 7.0. Figure 2 shows the function of citric acid and ammonium sulfate concentrations for ND \%, when the third variable sodium chloride is kept at its central level. The maximum response (ND $\%$ ) is found in the central contour region, where the concentration of ammonium sulfate ranges between 0.6 to $1.2 \mathrm{~g} \mathrm{~L}^{-1}$ and the concentration of citric acid ranges between 1.2 to $1.7 \mathrm{~g} \mathrm{~L}^{-1}$.

Figure 3 shows a surface contour plot to study the

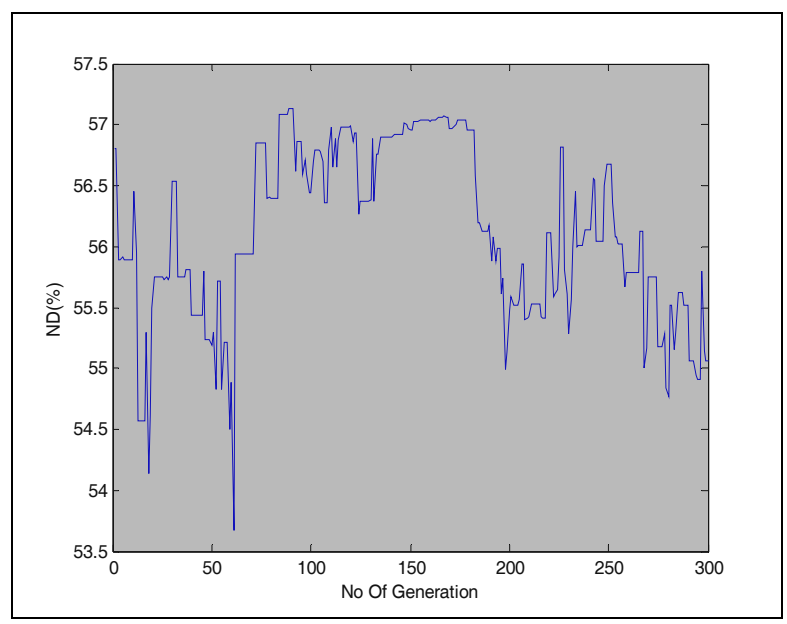

Figure 1: Graphical representation of the Fitness function (ND \%) over a number of generations of GA runs (300 generations).

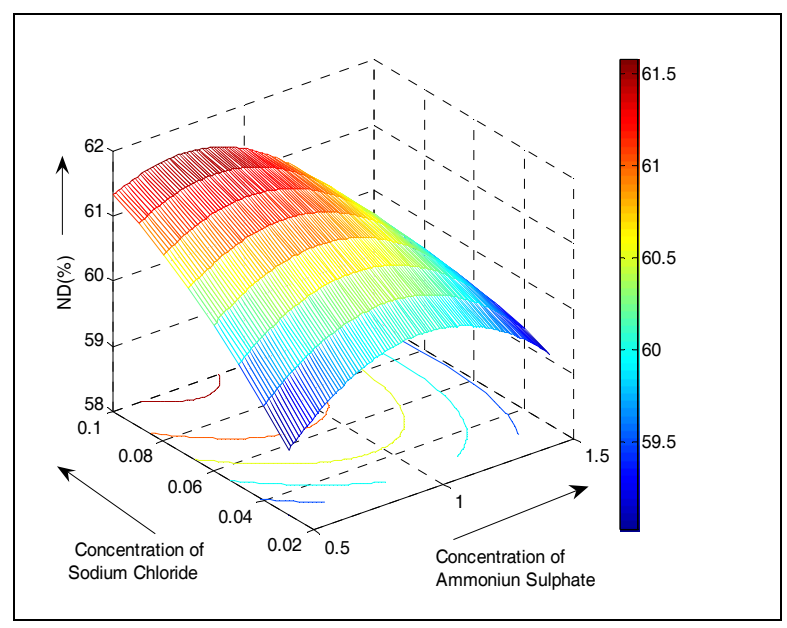

Figure 3: Response surface and contour plot view of varying effect of ammonium sulfate $\left(\mathrm{gL}^{-1}\right)$ and sodium chloride $\left(\mathrm{gL}^{-1}\right)$ when citric acid is at its central level. effect of ammonium sulfate and sodium chloride concentrations along with citric acid at its central level. The maximum fitness function (ND \%) is observed at high concentration of sodium chloride and middle range of concentration of ammonium sulfate.

Figure 4 shows a contour plot to illustrate the effect of concentrations of citric acid and sodium chloride (ammonium sulfate at central level) in terms of the fitness function (ND \%). The maximum fitness function is obtained at the combination of slightly higher concentration of sodium chloride and moderate values of concentration of citric acid.

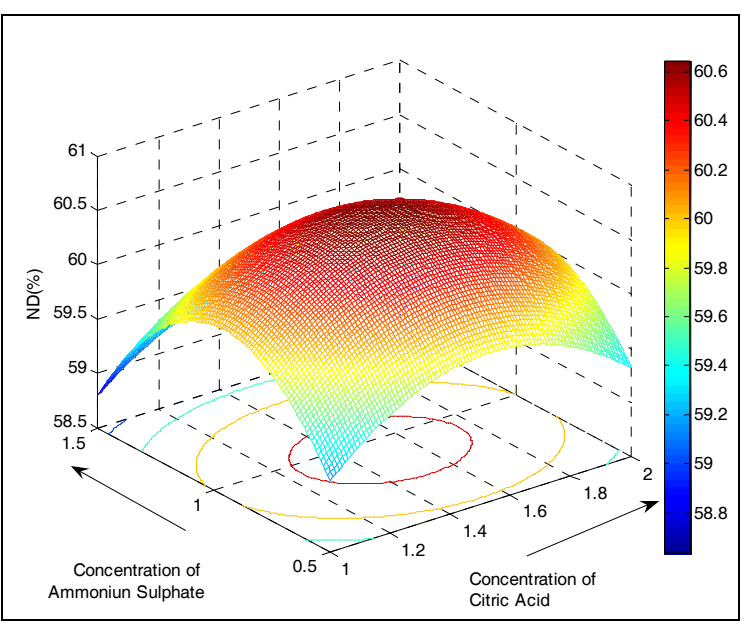

Figure 2: Response surface and contour plot view of varying effect of citric acid $\left(\mathrm{gL}^{-1}\right)$ and ammonium sulfate $\left(\mathrm{gL}^{-1}\right)$ when sodium chloride is kept at its central level.

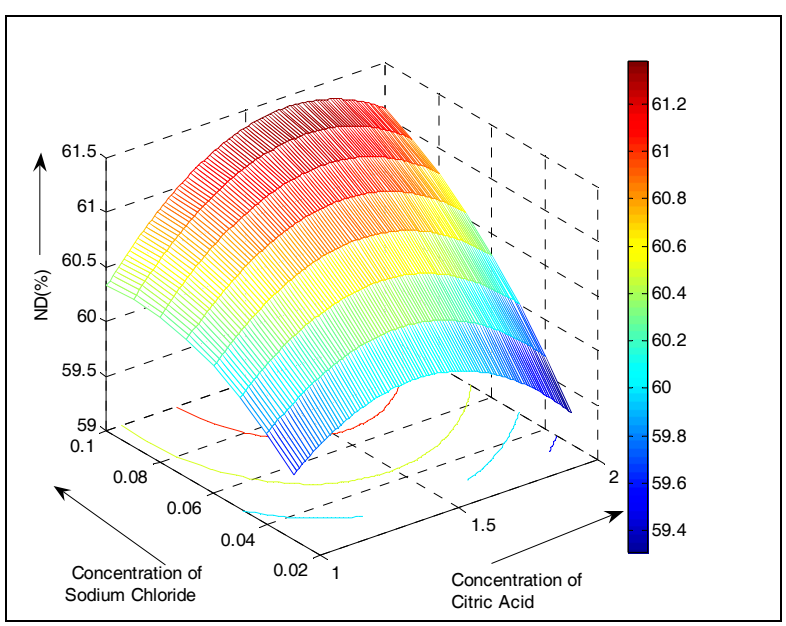

Figure 4: Response surface and contour plot view of varying effect of citric acid $\left(\mathrm{gL}^{-1}\right)$ and sodium chloride $\left(\mathrm{gL}^{-1}\right)$ when ammonium sulfate is at its central level. 


\section{CONCLUSION}

The biodegradation of naphthalene by using $P$. putida $\mathrm{S} 2$ has been studied in mineral medium given by Lee et al. (2003) with addition of citric acid. The Plakett-Burman design has been applied to screen the most significant variables with response on naphthalene degradation. Citric acid, $\left(\mathrm{NH}_{4}\right)_{2} \mathrm{SO}_{4}$, and $\mathrm{NaCl}$ have been found to be the most significant variables and their concentration levels have been further optimized by Genetic Algorithm based Response surface methodology using central composite design of experimentation. The relationship between predicted biodegradation efficiency and the medium variables (citric acid, $\left(\mathrm{NH}_{4}\right)_{2} \mathrm{SO}_{4}$, and $\left.\mathrm{NaCl}\right)$ was mathematically represented. The accuracy of the GA based RSM approach was confirmed by detailed validation of experiments carried out in a biphasic cultivation system. The maximum biodegradation efficiency of $55.51 \%$ was observed at concentrations of $1.0 \mathrm{~g} \mathrm{~L}^{-1}$, $1.0 \mathrm{~g} \mathrm{~L}^{-1}$, and $0.7 \mathrm{~g} \mathrm{~L}^{-1}$ for citric acid, ammonium sulfate and sodium chloride, respectively, with close prediction of biodegradation efficiency $(52.12 \%$ with $52.56 \%$ of experimental) at concentration of $1.5 \mathrm{~g} \mathrm{~L}^{-1}$, $0.5 \mathrm{~g} \mathrm{~L}^{-1}$, and $0.1 \mathrm{~g} \mathrm{~L}^{-1}$ for citric acid, ammonium sulfate and sodium chloride, respectively.

The interactive effect of significant medium variables was analyzed using three dimensional surface plots simulated by network output in terms of the maximum fitness function. The contour plots indicated the maximum naphthalene biodegradation in the moderate concentration range of citric acid, ammonium sulfate and slightly higher concentration range of sodium chloride. The results conclusively suggest that GA based RSM can be successfully adopted for the optimization of process variables for an in situ bioremediation process. The approaches presented in this paper may be adequately employed for large scale process modeling and optimization of bioremediation processes.

\section{NOMENCLATURE}

$\begin{array}{ll}\mathrm{A}, \mathrm{B}, \mathrm{C} & \begin{array}{l}\text { concentration of variables citric } \\ \text { acid, }\left(\mathrm{NH}_{4}\right)_{2} \mathrm{SO}_{4}, \text { and } \mathrm{NaCl} \\ \text { respectively, in equation } 3\end{array} \\ \mathrm{~b}_{1}, \mathrm{~b}_{2}, \mathrm{~b}_{3} & \begin{array}{l}\text { linear regression coefficient terms } \\ \text { in equation } 1\end{array} \\ \mathrm{~b}_{11}, \mathrm{~b}_{22}, \mathrm{~b}_{33} & \begin{array}{l}\text { square regression coefficient terms } \\ \text { in equation } 1\end{array} \\ \mathrm{~b}_{12}, \mathrm{~b}_{13}, \mathrm{~b}_{23} & \begin{array}{l}\text { interaction regression coefficient } \\ \text { terms in equation } 1\end{array}\end{array}$
$b_{o}$
$b_{t}$
D decimal equivalent of binary code in equation 3
$\mathrm{D}_{1}, \mathrm{D}_{2}, \mathrm{D}_{3} \quad$ dummy variables in the trials
$D_{c} \quad$ sum of all binary weights of each bit in equation 4
$\mathrm{fit}_{\text {max }}$, fit $\mathrm{req}_{\text {req }}$ maximum and required fitness of chromosome, respectively
L binary character string length
$\mathrm{N}$ number of chromosomes in the population in equation 5
$\mathrm{n} \quad$ length of chromosome in equation 6
$\mathrm{N}_{\mathrm{c}} \quad$ crossover between selected
ND \% percent Naphthalene Degradation in equation 7
$\mathrm{N}_{\mathrm{m}} \quad$ number of mutations
$\mathrm{pc} \quad$ crossover probability in equation 5
$\mathrm{P}_{\mathrm{m}} \quad$ mutation rate
$\mathrm{R}^{2} \quad$ determination of regression coefficients
$\mathrm{t}$-value test of significance (Student t-test)
$\mathrm{X}$ searching parameters (citric acid, $\left(\mathrm{NH}_{4}\right)_{2} \mathrm{SO}_{4}$, and $\mathrm{NaCl}$ ) in equation 3 $\mathrm{x}^{*} \quad$ decision variable vector which maximizes the objective function
$\mathrm{X}_{1}, \mathrm{X}_{2}, \mathrm{X}_{3} \quad$ coded value of variables citric acid, $\left(\mathrm{NH}_{4}\right)_{2} \mathrm{SO}_{4}$, and $\mathrm{NaCl}$, respectively
$\mathrm{x}_{1}, \mathrm{x}_{2}, \mathrm{x}_{3} \quad$ dimensional variables under optimal decision vector $\mathrm{x}^{*}$
$\mathrm{X}_{\max }, \mathrm{X}_{\min }$ maximum and minimum limits of $\mathrm{X}$ in equation 3
$\Sigma \mathrm{H}, \Sigma \mathrm{L} \quad$ summation of high and low responses of variables under trials respectively.

\section{Abbreviations}

$\begin{array}{ll}\text { ANN } & \text { Artificial neural network } \\ \text { ANOVA } & \begin{array}{l}\text { Analysis of variance } \\ \text { Central composite design } \\ \text { CCD }\end{array} \\ \text { CV } & \begin{array}{l}\text { Coefficient of variance } \\ \text { Genetic algorithm }\end{array} \\ \text { GA } & \text { Nicotinamide adenine dinucleotide } \\ \text { NADPH/ } & \begin{array}{l}\text { phosphate/ Nicotinamide adenine } \\ \text { NAnucleotide (reduced) }\end{array} \\ \text { NADH } & \text { Non-aqueous phase liquid } \\ \text { NAPL } & \text { Polycyclic aromatic hydrocarbons } \\ \text { PAHs } & \text { Predicted residual sum of square } \\ \text { PRESS } & \text { Response surface methodology } \\ \text { RSM } & \text { Standard deviation } \\ \text { SD } & \text { Stochastic universal sampling } \\ \text { SUS } & \end{array}$




\section{ACKNOWLEDGEMENTS}

One of the authors, Mr. Mohd.Zafar expresses his gratitude to the Ministry of Human Resources Development (MHRD), Govt. of India, New Delhi, for providing him a fellowship for pursuing doctoral studies.

\section{REFERENCES}

Annuar, M. S. M., Tan, I. K. P., Ibrahim, S. and Ramachandran, K. B., Ammonium uptake and growth kinetics of Pseudomonas putida PGA1. Asia Pacific Journal of Molecular Biology and Biotechnology, v. 14 (1), 1-10 (2006).

Ascon-Cabrera, M. and Lebeault, J. M., Selection of xenobiotic degrading microorganisms in a biphasic aqueous organic system. Applied and Environmental Microbiology, v. 59 (6), 17171724 (1993).

Boonchen, S., Britz, M. L. and Stanley, G. A., Degradation and mineralization of High-molecular weight Polycyclic Aromatic Hydrocarbon by Defined Fungal-Bacterial Cocultures. Applied and Environmental Microbiology, v. 66 (3), 1007-1019 (2000).

Cox, D. P., Kapicak, L. A. and Williams, A. C., The effect of glucose on naphthalene metabolism by Pseudomonas putida 119 in batch culture. FEMS Microbiology Letters, v. 5 (3), 197-199 (1979).

Desai, K. M., Akolkar, S. K., Badhe, Y. P., Tambe, S. S. and Lele, S. S., Optimization of fermentation media for exopolysaccharide production from Lactobacillus plantarum using artificial intelligence based techniques. Process Biochemistry, v. 41, 1842-1848 (2006).

Filonov, A. E., Karpov, A. V., Kosheleva, I. A., Puntus, I. F., Balashova, N. V. and Boronin, A. M., The efficiency of salicylate utilization by Pseudomonas putida strains catabolizing naphthalene via different biochemical pathways. Process Biochemistry, v. 35, 983-987 (2000).

Franco-Lara, E., Link, H. and Weuster-Botz, D., Evaluation of artificial neural network for modeling and optimization of medium composition with a genetic algorithm. Process Biochemistry, v. 41, 2200-2206 (2006).

Gaitonde, V. N., Karnik, S. R., Achyutha, B. T. and Siddeswarappa, B., GA application to RSM based models for burr size reduction in drilling. Journal of Scientific \& Industrial Research, v. 64, 347 (2005).

Kuntiya, A., Nicolella, C., Pyle, L. and Poosaran, N., Effect of sodium chloride on cell surface hydrophobicity and formation of biofilm in membrane bioreactor. Songklanakarin Journal of Science and Technology, v. 27 (5), 1073-1082 (2005).

Lee, K., Park, J. and Ahn, I., Effect of additional carbon source on naphthalene biodegradation by Pseudomonas putida G7. Journal of Hazardous Materials, B105, 157-167 (2003).

Martin, A. and Sivagurunathan, M., Optimization of the biodegradation of naphthalene by a microorganism isolated from petroleum contamination soil. Communication in Agricultural and Applied Biological Sciences, v. 68 (2Pt A), 175-180 (2003).

Mollea, C., Bosco, F. and Ruggeri, B., Fungal biodegradation of naphthalene: microcosms studies. Chemosphere, v. 60, 636-643 (2005).

Montgomery, D. C., Design and Analysis of Experiments. John Wiley \& Sons (Asia) Pvt. Ltd., Singapore (2004).

Moreira, G. A., Michelouf, G. A., Beccaria, A. J. and Goicoechea, H. C., Optimization of the Bacillus thuringiensis var. kurstaki HD-1 $\delta$-endotoxins production by using experimental mixture design and artificial neural networks. Biochemical Engineering Journal, v. 35, 48-55 (2007).

Nagata, Y. and Chu, H. K., Optimization of a fermentation medium using neural network and genetic algorithms. Biotechnology Letters, v. 25, 1837-1842 (2003).

Nigam, P., Banat, I. M., Marchant, R. and Singh, D., Degradation of naphthalene by bacterial culture. Environment International, v. 24 (5/6), 671-677 (1998).

Rao, S. C., Sathish, T., Mahalaxmi, M., Laxmi, G. S., Rao, S. R. and Prakasham R S., Modelling and Optimization of fermentation factors for enhancement of alkaline protease production by isolated Bacillus circulans using feed-forward neural network and genetic algorithm. Journal of Applied Microbiology, v. 104, 889-898 (2007).

Samanta, S. K., Singh, O. V. and Jain, R. K., Polycyclic aromatic hydrocarbons: environmental pollution and bioremediation. Trends in Biotechnology, v. 20 (6), 243-248 (2002).

Weuster-Botz, D., Experimental design for fermentation media development: Statistical design of global random search? Journal of Bioscience and Bioengineering, v. 90 (5), 473483 (2000).

Wilson, S. C. and Jones, K. C., Bioremediation of soil contaminated with polynuclear aromatic hydrocarbon (PAHs): A Review. Environmental Pollution, v. 81, 229-249 (1993). 